\title{
Effects of Healthy Eating Promotion on Food Preference of Head Start Preschoolers
}

\author{
Meizi He${ }^{1}$, Erica Sosa ${ }^{2}$, Alberto Cordova ${ }^{3}$, Summer Wilmoth ${ }^{4}$, David Bustos ${ }^{5}$, Arely \\ Perez $^{6}$ and Zenong Yin ${ }^{7}$ \\ 1,2,3,4,5,7 The University of Texas at San Antonio, Texas \\ ${ }^{6}$ Institute for Health Promotion Research, University of Texas Health Science Center San Antonio
}

Correspondence should be addressed to: Meizi He; meizi.he@utsa.edu

Received date: 16 June 2014; Accepted date: 23 September 2014; Published date: 21 December 2015

Academic Editor: Ewa Malecka-Tendera

Copyright (C) 2015. Meizi He, Erica Sosa, Alberto Cordova, Summer Wilmoth, David Bustos, Arely Perez and Zenong Yin. Distributed under Creative Commons CC-BY 4.0

\begin{abstract}
Objective: The healthy eating promotion strategies within the "Míranos" (Look at US, We Are Healthy) program aimed to increase fruit and vegetables (FV) intake, decrease sugary drinks while increase water consumption; as well as decrease energy-dense foods intake among preschoolers in Head Start Centers. Design: "Míranos!" was a one-school year intervention using a quasi-experimental pre-test/post-test design with two treatment groups and a comparison group. Two centers received a center-based intervention (T1), one center received a combined center- and home-based intervention (T2), and one center served as comparison. Healthy eating was promoted through classroom nutrition education, fruits and vegetable (FV) tasting, healthy eating contest and peer-parental nutrition education. Children's food preference was measured. GLM Univariate procedure was used to determine intervention effect. Setting: Head Start Centers Subjects: Study subjects were predominantly MexicanAmerican preschoolers $(n=356$; mean age $=4.1 ; 62 \%$ in normal weight range) enrolled in the participating Head Start Centers Results: Compared to the comparison group, T1 had significantly higher preference scores for FV $(p<0.05)$, while T2 had significantly higher preference scores for FV and water $(p<0.05)$. Conclusions: The "Míranos!" Program effectively improved preschoolers' preference in healthful foods. The combined center-based and home-based approach appears more promising than the center-based intervention alone. Word count: 205
\end{abstract}

Keywords: Preschooler; Healthy Eating; Head Start Center

\section{Introduction}

Obesity is the fastest growing health concern in the United States (US). (Ogden et al. 2006) The prevalence of obesity among children aged 2-5 years has reached $12.4 \%$.(Ogden, Carroll, Curtin,
McDowell, Tabak, \& Flegal 2006) These statistics are of particular concern for Hispanic children, who have the highest rates of obesity and who represent the largest, youngest, and fastest-growing minority group in the nation. Hispanic preschoolers, particularly boys, are

Cite this Article as: Meizi He, Erica Sosa, Alberto Cordova, Summer Wilmoth, David Bustos, Arely Perez and Zenong Yin (2015)," Effects of Healthy Eating Promotion on Food Preference of Head Start Preschoolers ", Journal of Research in Obesity, Vol. 2015 (2015), Article ID 830827, 
more likely to be overweight and obese than their non-Hispanic White counterparts. (Ogden et al. 2010) Clearly, these factors make it an urgent priority to redouble efforts to prevent obesity among Hispanic children.

Early childhood obesity is a complex, multifactorial health problem that results from the imbalance of energy intake and expenditure and dysregulation of energy balance behaviors. (De Craemer et al. 2012) For preschool children, the imbalance include dietary behaviors (e.g., a high-fat, low-fiber diet and heavy consumption of snacks and sugary drinks),(Wang et al. 2008) and physical activity (PA) behaviors (e.g., outdoor play, excessive screen time).(Reilly 2008) Although preschool children have the ability to regulate their energy intake, (Birch et al. 1991) their food preferences and eating habits during this time period are heavily influenced by parental feeding practices, ${ }^{\text {(Clark }}$ et al. 2007) access to healthy foods, and food environment.(Birch and Davison 2001) When preschoolers, especially obese preschool children, are served with larger portions of palatable, energy-dense entrées, their energy intake increases as intake of fruits and vegetables decreases. (Leahy et al. 2008) Studies also show that serving small entrée portions increase fruits and vegetables intake and decrease total energy intake in preschoolers. (Savage et al. 2012) Consumption of sugar-added drinks was found to positively relate to obesity, (Dubois et al. 2007) while water and limiting sugar drinks may reduce obesity in preschool children.(Wang, Bleich, \& Gortmaker 2008) Strategies for developing preferences for healthier food choices and eating habits, promoting positive parental feeding, and increasing availability of healthy foods can have an important impact on reducing excessive energy intake while increasing intake of healthier foods in preschool children. (Anon 2011)

Early childhood interventions may promote life-long healthy behaviors prior to the development of unhealthy behaviors. (Schmitz and Jeffery 2000;Steinbeck 2001) Child-care facilities are considered as important settings for early childhood obesity prevention. (Larson et al. 2011) In the USA, Head Start is a federally funded early childhood education program for nearly one million low-income preschool children with one third being overweight and obesity. Head Start programs provide comprehensive services to enrolled children and their families including health, nutrition, and social services. (The Office of Head Start (OHS) 2014) Head Start Programs present a promising venue for obesity prevention interventions among high risk Hispanic preschoolers. Recent recommendations have emphasized on the importance of using both environmental and behavioral approaches to address the childhood obesity problem. (Birch and Ventura 2009) As such, a comprehensive primary obesity prevention program "MIRANOS!" (Look at US, We Are Healthy) was implemented in Head Start Centers in San Antonio, Texas from September 2010 to April 2011. The effectiveness of the program on primary outcomes including BMI, physical activity level and food intake during lunch was reported by Yin et al.(Yin et al. 2012) The present paper specifically reports the healthy eating intervention strategies and their effects on Head Start preschoolers' food preference.

\section{Methods}

\section{Overview of “Míranos!” Study Design}

"Míranos!" was a one school-year culturally tailored, multicomponent prevention intervention to promote healthy weight gain and gross motor development in low-income preschoolers. (Yin, Parra-Medina, Cordova, He, Trummer, Sosa, Gallion, Sintes-Yallen, Huang, Wu, Acosta, Kibbe, \& Ramirez 2012) Study participants were predominantly Mexican-American preschoolers ( $\mathrm{n}=356$; mean age $=4.1 ; 62 \%$ in normal weight range) enrolled in the participating Head Start Centers. The study was conducted using a quasi-experimental pre-test/post-test design with two treatment groups and a comparison group. Two centers received a center-based intervention (T1), one center received a combined center- and homebased intervention (T2), and one center served as comparison. Geographical clustering as well as costs of study protocol implementation (staff travel and program cost) were the main considerations for deciding the treatment assignment. For example, the comparison center was five miles away from the intervention centers to avoid cross contamination. This study was conducted according to the guidelines laid down in the Declaration of Helsinki and all 
procedures involving human subjects/patients were approved by the XXXX. Written informed consent was obtained from parents of preschoolers. All preschoolers in the intervention centers were exposed to intervention activities, data were only collected from those with parental informed consent. The study design, intervention strategies and outcome measures of the "Míranos!" program were detailed by Yin et al (2012). (Yin, Parra-Medina, Cordova, He, Trummer, Sosa, Gallion, Sintes-Yallen, Huang, Wu, Acosta, Kibbe, \& Ramirez 2012)

\section{Descriptions of Healthy Eating Promotion Intervention Strategies}

Míranos! utilized theories of early childhood development and a system approach to modify daily eating and physical activity behaviors and provide an interactive, supportive learning environment for preschool children. (Birch \& Ventura 2009) Pre-school years (ages 3-5), a critical time in children's development of food and physical activity preferences and habits are heavily influenced by childcare providers, parents and families and prime opportunities for behavioral intervention. (Birch \& Ventura 2009) Following a systems approach, Míranos! targeted change agents at multiple levels and in multiple contexts (center and home environment, staff training and technical support, staff wellness, parent education and cultural integration) to create synergy for lasting changes in physical activity and dietary preference and habits in pre-school children.(Hesketh and Campbell 2010) Míranos! was implemented in two stages. Stage 1 (October 2010 to January 2011) established intervention program components and staff training. Stage 2 (January to April 2011) implemented all program components over a 18-week period. Overall Míranos! intervention strategies were described by Yin et al (2012). (Yin, Parra-Medina, Cordova, He, Trummer, Sosa, Gallion, Sintes-Yallen, Huang, Wu, Acosta, Kibbe, \& Ramirez 2012) The following is a specific description of the healthy eating intervention behavioral goals and strategies.

The healthy eating behavioral goals included increasing fruit and vegetables (FV), decreasing sugary drinks consumption while increasing water consumption; as well as decreasing energy-dense foods. Healthy eating was promoted through multiple strategies including Head Start staff development, classroom teaching, food tasting, and healthy eating contest in both the center-based (T1) and combined intervention groups (T2). Peer parental nutrition education was only implemented in the combined intervention group (T2).

\section{Center-Based Intervention Activities}

\section{- Staff development}

Head Start teachers, paraprofessionals and assistant center directors of intervention centers attended a 6-hour training during in-service at the beginning of the school year. This initial training provided general background and introduced the intervention strategies for center-based intervention activities. Follow-up trainings ( 4 hours) were conducted to address specific topics related to center-based intervention components. Since Head Start teachers and paraprofessionals have very limited training on nutrition, the staff development focused on increasing their health literacy (i.e. knowledge in obesity and nutrition) and teaching skills (e.g., role-modeling). Head Start center personnel could voluntarily participate in a wellness program, which offered free health screenings, counseling on healthy habits and health newsletters etc.

\section{- Classroom teaching}

Sesame Workshop's Healthy Habits for Life curriculum was used to help promote healthy eating. (Sesame Workshop 2014) Healthy Habits for Life is a bilingual health education program developed by child health experts using Sesame Street characters to promote physical activity and healthy eating habits in children ages 3-5. (Sesame Workshop 2014) The Nutrition Module consists of three chapters emphasizing the concepts of healthy eating (Table 1). 
Table 1: Sesame Workshop's Healthy Habits for Life Healthy Eating Topics

\begin{tabular}{|l|l|}
\hline \multicolumn{1}{|c|}{ Chapter } & \multicolumn{1}{c|}{ Topics } \\
\hline $\begin{array}{l}\text { Chapter 1: Nutritious } \\
\text { and Delicious! }\end{array}$ & Children explore wonderful and colorful foods. \\
\hline $\begin{array}{l}\text { Chapter 2: Making the } \\
\text { Healthy Choice }\end{array}$ & $\begin{array}{l}\text { Children discover what makes a healthy meal or } \\
\text { snack. They begin to understand that they can eat } \\
\text { certain healthy and nutrient-rich foods anytime, } \\
\text { but high-fat, sugary foods should be eaten only } \\
\text { sometimes. }\end{array}$ \\
\hline $\begin{array}{l}\text { Chapter 3: What My } \\
\text { Body Tells Me }\end{array}$ & $\begin{array}{l}\text { Children learn how to pay attention to their } \\
\text { bodies' signals. Are they hungry? Full? What } \\
\text { should they do with each of these signals }\end{array}$ \\
\hline
\end{tabular}

- The Healthy Habits for Life integrated a sense of fun and play into preschoolers' daily life and is practical, developmentally appropriate, and culturally relevant. The curriculum was taught by classroom teachers in classroom setting for four consecutive weeks. These teachers received prior training and on-site assistance from the research staff during curriculum delivery. Teachers completed a biweekly report on classroom activities (frequency, time of the day, and problems encountered) that served as an assessment of protocol implementation fidelity. Research staff also conducted weekly random classroom observations and provided necessary feedback during the curriculum delivery process.

\section{- $\quad$ Food tasting}

In an effort to repeatedly expose preschoolers to healthy foods that they learned in the classroom, fresh fruit and vegetables were served as snacks during afternoon snack time. Food tasting activities were implemented once per week for four consecutive weeks. The food items served were coincidently with the teaching topics of the Sesame Workshop's Healthy Habits for Life curriculum. For instant, a colorful rainbow FV tray was served when children explored the "wonderful and colorful foods" in Chapter 1. The FV items selected were based on their availability in local grocery stores, while not commonly served to Hispanic preschoolers such as broccoli, Kiwi, blueberries etc. One serving of either colorful fruits or vegetables was served at each food tasting events. Teachers were encouraged to serve as a role model by eating healthy foods, using water bottles for water, and avoiding soda in front of preschoolers. Teachers also reminded preschoolers of what they have learned from the Sesame Workshop curriculum.

\section{- Healthy eating contest}

Coincident with classroom Healthy Habits for Life Healthy Eating teaching and food tasting, preschoolers participated in a weekly healthy eating contest for four weeks to promote consumption of healthy foods. The weekly contest focused on one of the healthy food groups, i.e., fruits, vegetables, water or milk. In the 
water contest week, each child received a child-size water bottle to promote water consumption. Preschoolers received a happy-face sticker for consuming the healthy food items of the week during lunch or afternoon snack. These stickers were placed on a poster with their names in their classroom. Research staff tracked the number of stickers for each child and selected three winning preschoolers per class per week. The winners' names were recognized in the morning announcement the following Monday. The winning class of the week with the most stickers also received a trophy.

\section{Home-Based Intervention Activity}

\section{Parental Nutrition Education}

Míranos! aimed to create a home environment conducive for healthy eating and physical activity by providing a homebased intervention at one center-the combined center- and home-based intervention. The objective was to increase health literacy on obesity, nutrition, physical activity among parents and family members and providing at-home activities. A peer-led model was used to promote healthy eating among parents in the combined intervention group. Head Start centers require parents/guardians to physically sign their child in and out of class. Seizing on this opportunity to engage parents, seven parents were trained as peer educators to deliver an educational series on obesity prevention to other parents/guardians during dismissal time. Specifically, peer educators received nutrition education training prior to delivering the messages to their peer parents through a weekly "health fair" style education in the hallway during child pick up time. Three hallway "health fairs" were designated to cover key nutrition messages including the MyPlate food groups and serving size, "water instead of soda", and ways to encourage FV consumption among preschoolers. Peer educators approached parents as they arrived to pick up their child and invited them to view the posters. When parents agreed, they were escorted to the area inside the center where the posters were set up. Parents visited posters, interacted with parent peer educators, completed an information scavenger hunt worksheet and received a Take-Home Bag with a story book from class, healthy eating tips and family activities (e.g., making a healthy snack, using the water bottle for drinking water). Parents also received a different healthy snack (a piece of fresh fruit or a whole grain granola bar) after viewing the posters. It took 5 to 10 minutes for parents to complete these activities.

\section{Outcome Measures Related Healthy Eating Promotion}

Using a touch-screen computer, an interactive computerized instrument was used to assess preschoolers' food preference.(Jaramillo et al. 2006) This is an animated computer program measuring preschoolers' preference of fruits, vegetables and juices by asking them if the food item tasted "yummy," "yucky," or just "okay." The instrument show adequate testretest reliability $(\mathrm{r}=.70 ; \mathrm{p}<.01)$ and internal consistency of FJV items (Cronbach alpha $=.87)$. (Jaramillo, Yang, Hughes, Fisher, Morales, \& Nicklas 2006) For the purpose of the current study, two additional questions regarding water and milk were added into the testing process. The food preference measure was scored by averaging participants' responses in each category. (Jaramillo, Yang, Hughes, Fisher, Morales, \& Nicklas 2006) The measure can be used to yield an overall food preference score or to yield separate preference scores for fruits, fruit juices, vegetables, water and milk. Each food preference score ranged from 0 to 2 (0 for "yucky," 1 for "okay," and 2 for "yummy").(Jaramillo, Yang, Hughes, Fisher, Morales, \& Nicklas 2006)

Due to limited availability of touch-screen computers, food preference data were only collected from a sub-sample. Each center designated one class (the one with the highest enrollment) to take part in the food preference assessment at baseline and endpoint. 


\section{Data analysis}

Food preference scores were summed up to generate sub-food group scores (water, milk, fruits, vegetables, juices, French fries etc.). Data were analyzed using SPSS Statistics 21.0 (Armonk, NY: IBM Corp, 2012). GLM Univariate procedure was used to determine intervention effects on food preference scores between the two treatment group preschoolers and comparison preschoolers from post-test controlling for gender and pre-test measure. Significance level was set at $\mathrm{p}<.05$ with two-tailed test.

\section{Results}

Among the 356 preschoolers in the participating Head Start Centers, 91\% of parents gave informed consent at baseline $(\mathrm{n}=323)$ and $88 \%$ remained at endpoint $(\mathrm{n}=284)$. A sub-sample of 120 preschoolers were assessed for Food Preference, with 106 completed both pre- and post- test $(88 \%$ retention).

Table 2 shows that preschoolers in the center-based intervention group (T1) had a marginally higher water and milk preference score than those in the comparison group (Table 2). The combined intervention group (T2) also had a marginal higher milk preference score and a significantly higher water preference score than the control group.

Table 2: Milk and Water Preference Scores by treatment groups ${ }^{\S}$

\begin{tabular}{|c|c|c|c|c|c|c|c|c|c|}
\hline & & \multicolumn{2}{|c|}{$\begin{array}{l}\text { Comparison } \\
\text { (C) } \\
n=25\end{array}$} & \multicolumn{2}{|c|}{$\begin{array}{l}\text { Center-based } \\
\text { Intervention } \\
\text { (T1) } \\
\mathrm{n}=56\end{array}$} & \multicolumn{2}{|c|}{$\begin{array}{l}\text { Combined } \\
\text { Intervention } \\
\text { (T2) } \\
\mathrm{n}=25\end{array}$} & \multirow[t]{2}{*}{$\begin{array}{l}\text { \#Adjusted } \\
\text { Difference } \\
\text { T1 vs. C }\end{array}$} & \multirow[t]{2}{*}{$\begin{array}{l}\text { \#Adjusted } \\
\text { Difference } \\
\text { T2 vs. C }\end{array}$} \\
\hline & & Mean & SD & Mean & SD & Mean & SD & & \\
\hline \multirow{2}{*}{$\begin{array}{l}\text { Milk } \\
\text { (max } \\
\text { score=2) }\end{array}$} & Baseline & 1.72 & .61 & 1.46 & .76 & 1.64 & .64 & \multirow{2}{*}{$\begin{array}{l}0.12 \\
(p=0.09)\end{array}$} & \multirow{2}{*}{$\begin{array}{l}0.09 \\
\text { ns }\end{array}$} \\
\hline & Endpoint & 1.44 & .77 & 1.68 & .61 & 1.68 & .63 & & \\
\hline \multirow{2}{*}{$\begin{array}{l}\text { Water } \\
(\max \\
\text { score }=2)\end{array}$} & Baseline & 1.64 & .57 & 1.54 & .76 & 1.60 & .65 & \multirow{2}{*}{$\begin{array}{l}0.1 \\
\text { (ns) }\end{array}$} & \multirow{2}{*}{$\begin{array}{l}0.1 \\
(p<0.05)\end{array}$} \\
\hline & Endpoint & 1.76 & .60 & 1.77 & .54 & 1.96 & .20 & & \\
\hline
\end{tabular}

§ Scale from low to high: "Yucky" to "Yummy"

\# adjusted mean difference were controlled for baseline measure and gender

Table 3 shows that preschoolers in both the center-based (T1) and combined intervention groups (T2) had significantly higher scores for fruits (F), vegetables (V), and total FV than those in the comparison group. The intervention did not affect preschoolers' preference scores in either juices or French fries. 
Table 3: FV Preference Scores by treatment groups§

\begin{tabular}{|c|c|c|c|c|c|c|c|c|c|}
\hline & & \multicolumn{2}{|c|}{$\begin{array}{c}\text { Comparison } \\
\begin{aligned} \text { (C) } \\
n=25\end{aligned}\end{array}$} & \multicolumn{2}{|c|}{$\begin{array}{c}\text { Center- } \\
\text { based } \\
\text { Intervention } \\
\text { (T1) } \\
\text { n=56 }\end{array}$} & \multicolumn{2}{|c|}{$\begin{array}{c}\text { Combined } \\
\text { Intervention } \\
\begin{array}{c}\text { (T2) } \\
\text { n=25 }\end{array}\end{array}$} & \multirow[t]{2}{*}{$\begin{array}{c}\text { \#Adjusted } \\
\text { Difference } \\
\text { T1 vs. C }\end{array}$} & \multirow[t]{2}{*}{$\begin{array}{c}\text { \#Adjusted } \\
\text { Difference } \\
\text { T2 vs. C }\end{array}$} \\
\hline & & Mean & SD & Mean & SD & Mean & SD & & \\
\hline \multirow{2}{*}{$\begin{array}{l}\text { Fruits } \\
(\max \\
\text { score=22) }\end{array}$} & Baseline & 15.6 & 4.2 & 15.1 & 4.4 & 15.2 & 4.4 & \multirow[b]{2}{*}{$\begin{array}{c}0.66 \\
(p<0.05)\end{array}$} & \multirow[b]{2}{*}{$\begin{array}{c}3.2 \\
(p<0.01)\end{array}$} \\
\hline & Endpoint & 16.0 & 2.8 & 16.4 & 4.1 & 18.9 & 4.1 & & \\
\hline \multirow{2}{*}{$\begin{array}{l}\text { Vegetables } \\
\text { (max score } \\
=30)\end{array}$} & Baseline & 15.0 & 8.4 & 14.1 & 6.9 & 19.0 & 7.5 & \multirow[b]{2}{*}{$\begin{array}{c}4.5 \\
(p<0.05)\end{array}$} & \multirow[b]{2}{*}{$\begin{array}{c}7.7 \\
(p<0.05)\end{array}$} \\
\hline & Endpoint & 13.3 & 7.2 & 17.0 & 6.6 & 21.3 & 7.6 & & \\
\hline \multirow[b]{2}{*}{$\begin{array}{l}\text { Juices } \\
(\max \text { score }=8)\end{array}$} & Baseline & 6.5 & 1.8 & 5.8 & 2.0 & 5.8 & 2.3 & \multirow[b]{2}{*}{$\begin{array}{l}0.3 \\
\text { (ns) }\end{array}$} & \multirow[b]{2}{*}{$\begin{array}{c}0.9 \\
(p=0.05)\end{array}$} \\
\hline & Endpoint & 6.0 & 1.8 & 6.3 & 1.7 & 6.9 & 1.4 & & \\
\hline \multirow[b]{2}{*}{$\begin{array}{l}\text { French Fries } \\
(\max \text { score }=2)\end{array}$} & Baseline & 1.5 & .8 & 1.2 & .9 & 1.3 & .9 & \multirow[b]{2}{*}{$\begin{array}{l}0.2 \\
\text { (ns) }\end{array}$} & \multirow[b]{2}{*}{$\begin{array}{l}0.2 \\
\text { (ns) }\end{array}$} \\
\hline & Endpoint & 1.6 & .8 & 1.7 & .7 & 1.7 & .7 & & \\
\hline \multirow{2}{*}{$\begin{array}{l}\text { Fruit \& } \\
\text { Vegetables } \\
\text { (Max score = } \\
42 \text { ) }\end{array}$} & Baseline & 30.6 & 11.2 & 29.2 & 10.4 & 34.2 & 11.2 & \multirow{2}{*}{$\begin{array}{c}5.6 \\
(p<0.05)\end{array}$} & \multirow{2}{*}{$\begin{array}{c}10.8 \\
(\mathrm{p}<0.01)\end{array}$} \\
\hline & Endpoint & 29.4 & 8.4 & 33.4 & 9.9 & 40.2 & 11.5 & & \\
\hline
\end{tabular}

§ Scale from low to high: "Yucky" to "Yummy"

\# adjusted mean difference were controlled for baseline measure and gende

\section{Discussion}

“Míranos!” (Look at US, We Are Healthy) was a comprehensive primary obesity prevention program through the promotion of physical activities and healthy eating targeting Hispanic preschoolers in Head Start Centers. The findings indicate that MIRANOS! resulted in favorable preference changes in milk, water and FV. The combination of healthy eating lessons, healthful food tasting, healthy eating contests, as well as parental peer nutrition education appear promising in shaping preschoolers' healthy eating preference and habits.

It is encouraging that "Míranos!" resulted in favorable changes in preschoolers' preference toward healthful foods including milk, water, and FV with a shift from feeling "Yucky to 'Yummy'. Research has showed 
that children's exposure to healthful foods led to favorable changes in food preference.(Schindler et al. 2013) Our finding echoes research in both preschool and school-aged children. (Noradilah and Zahara 2012a;Taylor and Binns 2003;Wardle et al. 2003) It was suggested that 'exposure' is a promising technique for improving children's liking of vegetables (Wardle, Herrera, Cooke, \& Gibson 2003) and schools should provide exposure to a variety of healthy foods as part of their nutrition programs. (Schindler, Corbett, \& Forestell 2013) In the current context, we used healthful food tasting events coinciding with topics in the Sesame Street Healthy Eating Lessons, along with healthy eating contests and parental nutrition education to promote healthier eating behaviors. These strategies may all contribute to the favorable changes in healthful food preference, but not healthy foods, as children's preference toward French Fries in the current study remains relatively high, i.e., 1.7 out 2 ("Yummy"). A recent study revealed that the foods most preferred by children ages 3 to 4 were caloric dense foods. (De Lira-Garcia et al. 2012) Preschoolers' preference toward healthful foods in the current study was further reflected by the lunch food intake patterns. (Yin, Parra-Medina, Cordova, He, Trummer, Sosa, Gallion, SintesYallen, Huang, Wu, Acosta, Kibbe, \& Ramirez 2012) Indeed, research showed that school aged children "who liked a food a lot" consumed 0.5 to 2.7 more weekly servings of the food than did children who did not like the food" (Noradilah and Zahara 2012b) and that "introducing children to unfamiliar fruits and vegetables through taste testing may be an effective and practical health promotion approach

for improving dietary habits". (Noradilah \& Zahara 2012b)

It is also important to explore if the combined center- and home- based intervention (T2) results in a greater impact on preschoolers' eating preference and behaviors than the center-based alone intervention (TI). The magnitude of changes appears greater in the center- and home based intervention group than the centerbased alone group, showing the importance of parental and family influences on children's preferences toward healthful foods. Data from parents' questionnaire from the current study also indicated that preschoolers in the combined intervention group consumed less soda, other sugary drinks, candy and sweets than the comparison group, while such trends did not exhibit in the center-based alone intervention group.(Yin, Parra-Medina, Cordova, He, Trummer, Sosa, Gallion, Sintes-Yallen, Huang, Wu, Acosta, Kibbe, \& Ramirez 2012) Given the fact that preschoolers' eating patterns are largely under the influence of their parents, (Klesges et al. 1986) combining center- and home-based intervention is more likely to sustain children's healthy eating behaviors. The peer parental nutrition education in the current study certainly may have contributed in increasing parental health literacy and skills, resulting in a healthier home food environment which is conducive for preschoolers' growth and development.

There were a number of limitations associated with this study. First, the study used a quasi-experimental design which may compromise internal validity. Second, due to a limited availability of touch screen computers, only a sub-sample of study subjects was assessed for food preference. The relative small sub-sample size limited statistical power in detecting intervention effect on food preference scores. Third, preschoolers' dietary intake at home was not assessed.

\section{Conclusions}

The "Míranos!" Program effectively improved preschoolers' preference in healthful foods. The combined center-based and home-based approach appears more promising than the center-based intervention alone. Future research should further develop intervention means to undo children's preference toward unhealthy foods.

Acknowledgments: The research team wants to thank the preschoolers, parents, administrators, teachers and staff of Head Start Centers in San Antonio, TX, and the Family Service Association of San Antonio, which participated in and supported this project. Funding for this project was provided by the San Antonio Life Sciences Institute, San Antonio, TX, and the International Life Sciences Institute Research Foundation, Washington, DC. 
Ethics of Human Subject Participation: The study protocol was reviewed and approved by the Institutional Review Board (IRB) at The University of Texas at San Antonio

\section{References}

\section{2011. Early Childhood Obesity Prevention} Policies The National Academies Press.

2. Birch, L.L. \& Davison, K.K. 2001. Family environmental factors influencing the developing behavioral controls of food intake and childhood overweight. Pediatr.Clin.North Am., 48, 893-907

3. Birch, L.L., Johnson, S.L., Andresen, G., Peters, J.C., \& Schulte, M.C. 1991. The variability of young children's energy intake. The New England Journal of Medicine, 324, (4) 232-235 available from: PM:1985244

4. Birch, L.L. \& Ventura, A.K. 2009. Preventing childhood obesity: what works? Int.J.Obes.(Lond)., 33 Suppl 1:S74-81., S74S81

5. Clark, H.R., Goyder, E., Bissell, P., Blank, L., \& Peters, J. 2007. How do parents' childfeeding behaviours influence child weight? Implications for childhood obesity policy. $J$ Public Health (Oxf), 29, (2) 132-141 available from: PM:17442696

6. De Craemer, M., De Decker, E., De Bourdeaudhuij, I., Vereecken, C., Deforche, B., Manios, Y., Cardon, G., \& ToyBox-study group 2012. Correlates of energy balance-related behaviours in preschool children: a systematic review. Obesity Reviews, 13, 1328 available from: http://dx.doi.org/10.1111/j.1467-

789X.2011.00941.x

7. De Lira-Garcia, C., Bacardi-Gascon, M., \& Jimenez-Cruz, A. 2012. Preferences of healthy and unhealthy foods among 3 to 4 year old children in Mexico. Asia Pac.J.Clin.Nutr., 21, (1) 57-63 available from: PM:22374561

8. Dubois, L., Farmer, A., Girard, M., \& Peterson, K. 2007. Regular sugar-sweetened beverage consumption between meals increases risk of overweight among preschool-aged children. J Am Diet Assoc,
107, (6) 924-934 available from: PM:17524711

9. Hesketh, K.D. \& Campbell, K.J. 2010. Interventions to prevent obesity in 0-5 year olds: an updated systematic review of the literature. Obesity (Silver.Spring), 18 Suppl 1, S27-S35 available from: PM:20107458

10. Jaramillo, S.J., Yang, S.J., Hughes, S.O., Fisher, J.O., Morales, M., \& Nicklas, T.A. 2006. Interactive computerized fruit and vegetable preference measure for African-American and Hispanic preschoolers. J.Nutr.Educ.Behav., 38, (6) 352-359 available from: PM:17142191

11. Klesges, R.C., Malott, J.M., Boschee, P.F., \& Weber, J.M. 1986. The effects of parental influences on children's food intake, physical activity, and relative weight. International Journal of Eating Disorders, 5, (2) 335-345 available from: http://dx.doi.org/10.1002/1098108X(198602)5:2<335::AIDEAT2260050212>3.0.CO;2-T

12. Larson, N., Ward, D.S., Neelon, S.B., \& Story, M. 2011. What role can child-care settings play in obesity prevention? A review of the evidence and call for research efforts. $J$ Am Diet.Assoc., 111, (9) 1343-1362 available from: PM:21872698

13.Leahy, K.E., Birch, L.L., \& Rolls, B.J. 2008. Reducing the energy density of multiple meals decreases the energy intake of preschool-age children. Am J Clin Nutr, 88, (6) 1459-1468 available from: PM:19064504

14.Noradilah, M.J. \& Zahara, A.M. 2012a. Acceptance of a test vegetable after repeated exposures among preschoolers. Malays.J.Nutr., 18, (1) 67-75 available from: PM:23713231

15. Noradilah, M.J. \& Zahara, A.M. 2012b. Acceptance of a test vegetable after repeated exposures among preschoolers. Malays.J.Nutr., 18, (1) 67-75 available from: $\mathrm{PM}: 23713231$

16. Ogden, C.L., Carroll, M.D., Curtin, L.R., Lamb, M.M., \& Flegal, K.M. 2010. Prevalence of high body mass index in US children and 
adolescents, 2007-2008. JAMA., \%20;303, (3) 242-249

17. Ogden, C.L., Carroll, M.D., Curtin, L.R., McDowell, M.A., Tabak, C.J., \& Flegal, K.M. 2006. Prevalence of overweight and obesity in the United States, 1999-2004. JAMA., 295, (13) 1549-1555

18. Reilly, J.J. 2008. Physical activity, sedentary behaviour and energy balance in the preschool child: opportunities for early obesity prevention. Proc.Nutr Soc, 67, (3) 317-325 available from: PM:18700053

19. Savage, J.S., Fisher, J.O., Marini, M., \& Birch, L.L. 2012. Serving smaller ageappropriate entree portions to children aged 3-5 y increases fruit and vegetable intake and reduces energy density and energy intake at lunch. Am J Clin Nutr, 95, (2) 335341 available from: PM:22205315

20. Schindler, J.M., Corbett, D., \& Forestell, C.A. 2013. Assessing the effect of food exposure on children's identification and acceptance of fruit and vegetables. Eat.Behav., 14, (1) 53-56 available from: PM:23265402

21. Schmitz, M.K. \& Jeffery, R.W. 2000. PUBLIC HEALTH INTERVENTIONS FOR THE PREVENTION AND TREATMENT OF OBESITY. Medical Clinics of North America, 84, (2) 491-512 available from: http://www.sciencedirect.com/science/arti cle/B75JC-4GGXMJNG/2/6fd1633d01f6b485246019105adabc7c

22. Sesame Workshop. Healthy Habits for Life

http://www.sesameworkshop.org/what- we-do/our-initiatives/healthy-habits-forlife/ accessed on 2014. 4-20-2014.

23. Steinbeck, K.S. 2001. The importance of physical activity in the prevention of overweight and obesity in childhood: a review and an opinion. Obes.Rev., 2, (2) 117130 available from: PM:12119663

24. Taylor, J. \& Binns, D. 2003, Evaluation of a Fruit \& Vegetabl Pilot Program for Elementary School Children in Prince Edward Island, Prince Edward Island Healthy Eating Alliance, Prince Edward Island.

25. The Office of Head Start (OHS), A. o. C. a. F. T. D. o. H. a. H. S. Head Start. 2014. 4-202014.

26. Wang, Y.C., Bleich, S.N., \& Gortmaker, S.L. 2008. Increasing caloric contribution from sugar-sweetened beverages and $100 \%$ fruit juices among US children and adolescents, 1988-2004. Pediatrics, 121, (6) e1604-e1614 available from: PM:18519465

27. Wardle, J., Herrera, M.L., Cooke, L., \& Gibson, E.L. 2003. Modifying children's food preferences: the effects of exposure and reward on acceptance of an unfamiliar vegetable. Eur J Clin Nutr, 57, (2) 341-348 available from: http://dx.doi.org/10.1038/sj.ejcn.1601541

28. Yin, Z., Parra-Medina, D., Cordova, A., He, M., Trummer, V., Sosa, E., Gallion,

29. K.J., Sintes-Yallen, A., Huang, Y., Wu, X., Acosta, D., Kibbe, D., \& Ramirez, A. 2012. Miranos! Look at us, we are healthy! An environmental approach to early childhood obesity prevention. Child Obes., 8, (5) 429439 available from: PM:23061498 